\title{
BIOMECHANICAL EVALUATION OF THREE DIMENSIONAL TITANIUM MINIPLATES IN MANDIBULAR FRACTURE FIXATION
}

\author{
Mohamd Ali Ibrahim Sakr*, Wael Ahmad El-Mohandes*** and Ahmad A. H. Elfekey***
}

\begin{abstract}
The unique position of mandible on the face makes it one of the most commonly fractured facial bones and considered the most common fractures treated by oral and maxillofacial surgeon. There are a number of methods used till date for the treatment of mandibular fractures. Traditionally, the treatment modalities have ranged from conservative measures such as maxillomandibular fixation by means of wiring, splints or arch bar fixation to open reduction with fixation. Most authorities today, advise open reduction and fixation by plates and screws which is necessary for most of the mandibular fractures.
\end{abstract}

The purpose of this study was to biomechanically evaluate the properties of the 3 dimensional titanium mini plates in mandibular fractures fixation.20 sheep hemi mandibles were selected, prepared and randomly divided into 2 groups: 1). Bending test group (compression group) : 10 hemimandibles with induced body fracture and 2). Tensile test group (tension group): 10 hemimandibles with induced body fracture. The specimens of both groups were treated with the same fixation system (plates \& screws) and prepared for mechanical testing using universal testing machine. A specifically designed custom made 4-point biomechanical test jig was fabricated to be adapted to universal testing machine. A load range of 0-400 Newtons was progressively applied by the machine at a constant head speed of $10 \mathrm{~mm} / \mathrm{min}$. The progression of loading and displacement either vertically or laterally was followed on the machine monitor, and the load value data in Newton, and extent in millimeters (mm) of any resulting displacement or fixation loosening observed between the two fractured segments during the experiment were noted. The experimental end point was defined as permanent deformation (twisting/fracture) of the plate and/or looseness of mini-screws. The loadldisplacement data were recorded and the yield load and yield displacement and stiffness were observed and transmitted to a computer that generated a data spreadsheet of force versus displacement. The data referring to the maximum force needed to bring instability and failure to the system were collected and subjected to statistical analysis. In the present study ,the results of the mean yield compression and tension stresses revealed that the used fixation system proofed to be highly efficient for supporting the fracture during the period of osteosynthesis, as their point of deformation under load is far away from the reported maximum forces suitable for normal osteosynthesis processes. Three dimensional miniplates are easy to adjust, requires minimal tissue dissection thus least disturbance to the tissues. Its low profile design and space between plate holes permits excellent revascularization. Comparing the three dimensional plating system with conventional systems, only fewer plates and screws are needed to stabilize the bone fragments.

\section{INTRODUCTION}

Face is the window through which we perceive the world around us and the world notes us. The face is crucial, injuries to face results in divesting physical and emotional sequelae. Maxillofacial trauma is a cause of grave concern due to the increasing road traffic accidents, violence and sports injury. The unique position of mandible on the face makes it one of the most commonly fractured facial bones. Mandibular Fractures are the most common fractures treated by oral and maxillofacial surgeon. Fractures of mandible occur more commonly than any other fractures of facial

\footnotetext{
* General Dentist,

** Ass. Professor, Department of Oral and Maxillofacial Surgery, Faculty of Dental Medicine, Boys, Cairo, Al-Azhar University,

*** Lecturer of Oral and Maxillofacial Surgery, Faculty of Dental Medicine, Boys , Cairo, Al-Azhar University.
} 
skeleton.Significantly decreasing the mechanical strength of the mandible can lead to fracture. If such a fracture is due to changes in the turnover of the bone or the development of a resorptive lesion such as a tumor, then such a fracture is called pathologic fracture. When the fracture is directly due to the impact of medical interventions such as removal of a third molar of faulty osteotomy design, then such a fracture is called an Iatrogenic fracure ${ }^{(1)}$.

In particular, a fracture may occur in any anatomically normal bone that is loaded beyond its tolerance ${ }^{(2)}$. Fracture may also occur in a bone that has been weakened by an underlying pathologic process, even if the forces to which it are subjected would usually be tolerated. Such fractures are called pathologic fractures ${ }^{(3,4)}$. The bone of the oro-facial skeleton is most commonly involved in pathologic fractures is the mandible ${ }^{(1)}$.

Mandibular fractures most commonly accompany facial trauma, with nearly half of the patients requiring surgical repair. $75 \%$ of fractures occur in males aged 20-30, and are often caused by physical assault; other causes include motor vehicle collisions, falls, and sports-related injury. Certain fracture patterns predominate ${ }^{(5,6)}$. Early investigators showed the linear fracture of long bone were initiated by bone failure resulting from tensile strain rather compressive strain ${ }^{(7-9)}$. Huelke and Harger (1969) ${ }^{(8)}$ applied forces of varying magnitudes and direction to dried mandibles and observed the resultant production of tension and compression. They found that $>75 \%$ of all experimentally produced fractures of the mandible were in primary areas of tensile strain, which supported a similar observation made earlier in long bone. A notable exception was that comminuted condylar head injury that was produced by a load parallel to the mandibular ramus was primarily the result of compressive force. When a force is directed along the parasymphysis-body region of the mandible, compressive strain develops along the buccal aspect, whereas tensile strain develops along the lingual aspect. This produces a fracture that begins in the lingual region and spreads toward the buccal aspect ${ }^{(10)}$.

Treatment of mandibular fractures has made significant advances over the years due to improved understanding of biomechanical principles, advances in biomaterials and instrumentation, and scientifically based research of treatment outcomes. The therapeutic goals in the treatment of such kinds of fractures depend on the arrangement of the bone fragments in their anatomical position, restoring functionality with least morbidity, and providing fracture stabilization. Treatment choices include closed or open techniques ${ }^{(7)}$.

The basic concept of three dimensional fixations is that a geometrically closed quadrangular plate secured with bone screws creates stability in three dimensions. The three dimensional plates are positioned parallel to fracture line. The cross linking provides the stability to the system.. The principle of the 3D fixation is further based on the idea that the plate is not positioned along the trajectories but over the weak structure lines. The fixation points of the plate remain in the vicinity of the fracture or osteotomy line (Fig.1) ${ }^{(10,11)}$.

The biomechanical and technical advantage of three dimensional miniplate systems promoted the current study to evaluate the biomechanical efficacy of three dimensional titanium miniplates as a viable treatment modality in the osteosynthesis of mandibular body fractures.

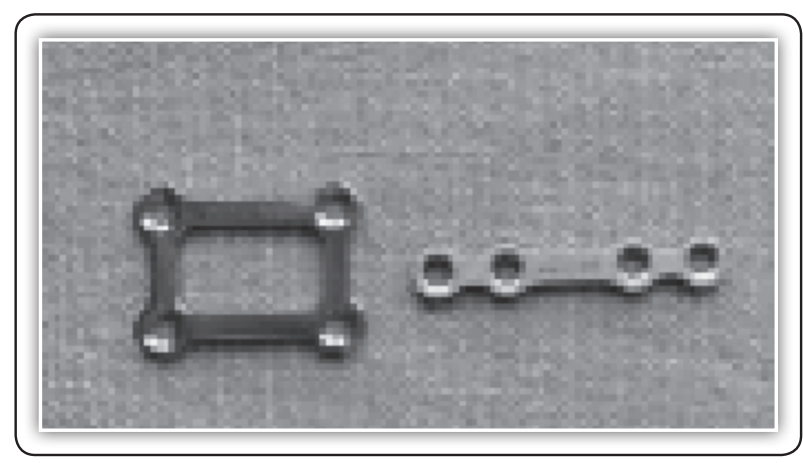

FIG (1) 3D plate and miniplate 
Various researches showed that the 3D plating system offers more favorable biomechanical behavior than the conventional miniplates in terms of stability and strain resistance in different regions of mandible ${ }^{(12-14)}$. The $1 \mathrm{~mm}$ standard 3D plate can withstand traction forces with value of $690 \mathrm{~N}$ which are almost the value of maximum load capacity of the mandible ${ }^{(15)}$. The newly introduced 3D plating system provides definite advantages over conventional miniplates. The $3 \mathrm{D}$ plating system uses fewer plates and screws as compared to conventional miniplates to stabilize the bone fragments. Thus it uses lesser foreign material, reduces the operation time and overall cost of the treatment as described by Zix et al (2007)(12) and Farmand et al (1992)(16). The 3D plating system has a compact design and is easy to use. The $1.0 \mathrm{~mm}$ thick $3 \mathrm{D}$ plate is as stable as the much thicker $2-0 \mathrm{~mm}$ miniplate. This offers better bending stability and more resistance to out of plane movement or torque ${ }^{(12)}$. Whether one method is superior to another or not, it is difficult to determine, Zix et al (2007) ${ }^{(12)}$ concluded that $3 \mathrm{D}$ plating system is an easy to use alternative to conventional miniplates to treat mandibular angle fractures. Various researches show that the 3D plating system offers more favorable biomechanical behavior than the conventional miniplates in terms of stability and strain resistance in different regions of mandible ${ }^{(12,13-16)}$.

A biomechanical study investigated the effectiveness of fixation by 3-dimensional plates of simulated angle fractures in sheep mandible. It was shown that there was no failure in bone/screw interface. The results indicated that a 3-D plate can be used for fixation of mandibular angle fracture ${ }^{(17)}$. Ricalde et al (2005) ${ }^{(18)}$ conducted a study using Red oak wood board to simulate the mandible. Titanium and resorbable plates and screws in various configurations were used to stabilize pieces of the wood. They were arranged in 6 different groups. The specimens were individually tested with a vertical load, while the test machine recorded the force- versus-displacement behavior automatically and concluded that the Overall, the titanium system was studied exhibited greater resistance to deformation from a vertical load than did the resorbable plate groups. The aim of the present study is an invitro study was to biomechanically evaluate the properties of the 3 dimensional titanium mini plates in mandibular fractures fixation.

\section{MATERIALS AND METHODS}

After the approval by the research ethical committee, 10 adult sheeps were used in this study with similar age (9-11 months) housed under optimum conditions for 3 weeks being fed a natural diet till the time of experiment. The selected sheeps were sacrificed.10 sheep mandibles with complete sets of teeth were separated from the skull and, were kept frozen at 40c till time of preparation.

\section{Preparation of the fresh sheep mandibles includ- ed the following,(Fig2):}

- At room temperature, the mandibles were stripped of their soft tissue by a sharp dissector and divided in the anterior midline between the central incisors at the chin area using a bi-beveled 1.5 surgical osteotome 20 hemimandibles (right and left halves)

- The specimens were measured (height and width of the ramus, length of the mandible and distance between the anterior limit of the foramen and the anterior border of the mandible) because the use of mandibles of disproportional sizes could interfere in the mechanical test.

- The coronoid and condylar process were removed to avoid difficulty of fixation on the test jig during load application. For creation of standrdized osteotomies that simulate mandibular body fractures amoung all samples, a fracture line was determined by the aid of a prefabricated acrylic resin prefabricated guide and using fine band saw. 
- The fracture line was planned to be situated midway between the last molar and the first molar (body area), bicortically \& extending in oblique direction from superior border of mandible to inferior border of mandible. A wedge shape notch was done at inferior border to prevent resistance of bone to the load in the aim of characterizing of titanium miniplates material.

- The models were then uniformly sectioned with thin metal disc at low speed rotation and under copious saline irrigation following the predetermined fracture line. A wedge shape indentation was made at inferior border to prevent resistance of bone to the load in the aim of characterizing of titanium miniplates material. Soon afterwards, the selected experimental units were kept moist and refrigerated until all testing was complete.

- The 20 prepared animal specimens were equally and randomly divided into 2 groups:

1. Bending test group (compression group): 10 hemimandibles with induced body fracture

2. Tensile test group (tension group): 10 hemimandibles with induced body fracture

- The specimens of both groups were treated with the same fixation system (plates \& screws) and prepared for mechanical testing.

\section{Application of the fixation system:}

- The proximal and distal segments were repositioned to original places by means of self retained bone forceps.

- The three dimensional mini plates were adapted by means of plate bending pliers and were placed on their planned sites, and preplanned sites of screw holes were marked such that, two holes were planned on each side of the induced fracture line of which one hole is about 4-5 mm below the crestal bone and the other is $2 \mathrm{~mm}$ above the inferior border of the mandible.
- Screw holes were drilled using $1.5 \mathrm{~mm}$ titanium drill driven by straight hand piece with a speed ranging from 6000-7000 RPM with cooling system \& high torque. While the plate is in its place and screws are situated in the proper position, a screw driver with holding forceps was used to bring the screws into their proper places within their holes \& fixation was confirmed. At the time of miniplate screwing, the hemi-mandible was stabilized using drops of prefabricated self polymerizing resin and the miniplates positioned to make perforation possible.

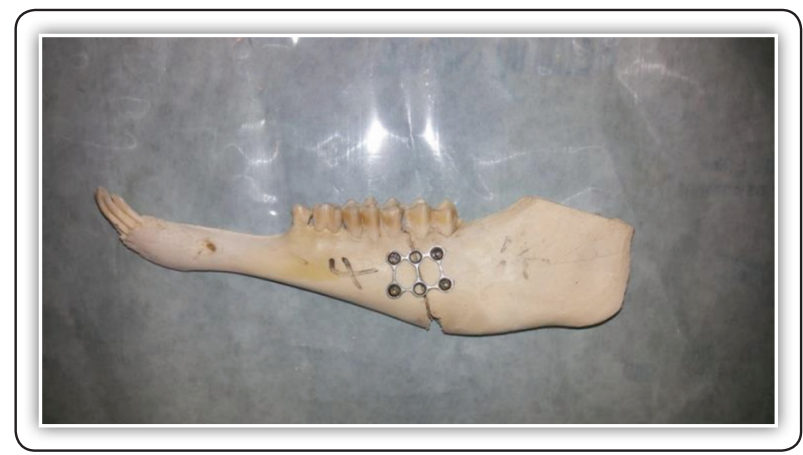

FIG (2) Prepared sample ready for the mechanical testing

\section{Application of loads (Mechanical testing)}

\section{a) Testing devices:}

\section{1) Testing machine:}

The hemimandibles of both groups were submitted to compression (group 1) and tensile loading (group 2) tests using the universal testing machine LLOYD LR- $5 \mathrm{kN}$ model(Lloyd Instruments LTD, Segensworth, Fareham, England), connected to a computer with a specialized software. This machine used a testing procedure in which the forces applied by the masticatory muscles were simulated in vitro. The models were positioned in such a way as to allow examination of the resistance of the osteosynthesis methods during simulated mastication. The loads were progressively applied by the machine at a constant head speed of $10 \mathrm{~mm} /$ min and with forces measured in (Newtons) and all data were transferred and recorded with the connected computer. 


\section{2) Bending (compression) test device:}

For testing purposes, a specifically designed custom made 4-point biomechanical test jig was fabricated to be adapted to universal testing machine.

\section{3) Tension test device:}

Two custom made metallic hooks were fabricated to be fixed to the upper and lower parts of the universal testing machiene and were attached to the machiene parts with the same mechanism as Bending (compression) test device.

\section{Mechanical testing procedures :}

\section{1) Bending (compression) test :}

- The custom made bending test device was attached to the testing machiene and was used for compression test for Group (1) prepared samples.The samples were stabilized \& firmly hold from ramus of mandible and incisor region with the aid of the lower compartment of custom made biomechanical test jig, as the elevated grooved bars represented a scaffold that will act as fulcrum to induce torque in the sample during loading.

- The mandibles with plating systems were progressively loaded with Continuous linear vertical compressive loads that simulate the masticatory loads ranging from 0-400 N(107). Loading was increased till failure of the plating system occurred (Fig.3).

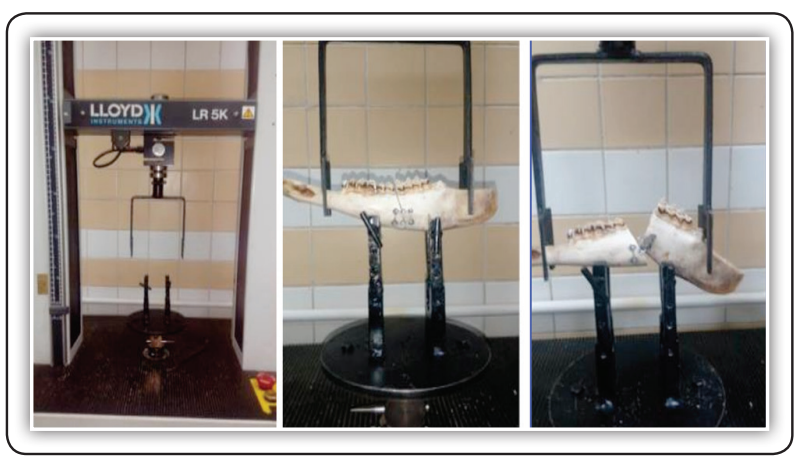

FIG (3) Compression Testing procedures

\section{2) Tensile test :}

* The custom made tension test device was attached to the testing machiene and was used for tension test for Group (2) prepared samples that were stabilized \& firmly hold by the custom made device hooks attached to testing machiene from the distal and proximal ends.

* The tensile test was performed by applying shear peal forces along the length of the attached speciemen starting from zero point till failure of the plating system occurred (Fig.4).

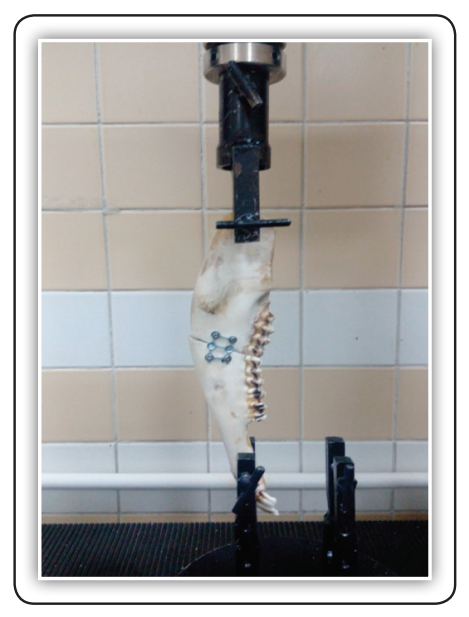

FIG (4) Tension test procedure.

\section{3) Force displacement measurement:}

For both tests, displacement measurements was obtained using a precaliperated linear variable displacement transducer (LVDT) that was attached to the universal testing machine.

\section{4) Data collection:}

* The progression of loading and displacement either vertically or laterally was followed on the machine monitor, and the load value data in Newton, and extent in millimeters $(\mathrm{mm})$ of any resulting displacement or fixation loosening observed between the two fractured segments during the experiment were noted. 
* The experimental end point was defined as permanent deformation (twisting/fracture) of the plate and/or looseness of miniscrews.

* Loadldisplacement data were recorded and the yield load(maximum force needed to bring instability and failure to the system ) and yield displacement and stiffness were observed.

* The data were transmitted to a computer that generated a data spreadsheet of force versus displacement.

* Data were presented as means, standard deviation (SD), standard error (SE), minimum values at which the displacement begins and maximum values. All of the quantitative data were analyzed statistically using IBM SPSS Statistics for Windows, version 20.0 (IBM Corp., Armonk, NY, USA).

\section{RESULTS}

The current study consisted of two parts and was used to evaluate the biomechanical properties of three dimensional titanium miniplates. During the experiment 20 6-holed (3x2) 3D titanium miniplates were used, each was fixed by 4 mini screws with a total of 80 mini titanium screws in 20 sheep hemi mandibles. The loads were applied until the failure (permenant deformation] of the fixation system occurred which was considered the end point of failure.

\section{A). Mode of specimens failure under loading: (Table 1)}

TABLE (1): Statistical analysis of different modes of fixation failure amoung specimens of both groups

\begin{tabular}{|c|c|c|}
\hline \multirow{2}{*}{ Failure mode } & Group 1 & Group 2 \\
\cline { 2 - 3 } & Compression & Tension \\
\hline Plate fracture & 3 & 0 \\
\hline Plate twisting only & 4 & 7 \\
\hline $\begin{array}{c}\text { Plate twisting and screw } \\
\text { avulsion }\end{array}$ & 1 & 1 \\
\hline Screws avulsion only & 2 & 2 \\
\hline Total & 10 & 10 \\
\hline
\end{tabular}

\section{B). Statistical analysis of the recorded print out chart data for each group:}

The yield load, yield displacement and stiffness data were collected according to the print out charts of the universal testing machine and statistically analysed. Data were presented as means, standard deviation (SD), standard error (SE), minimum and maximum values. Student's t-test was used to compare between the two groups and between Yield load and displacement in the same group. The significance level was set at $\mathbf{p} \mathbf{\leq 0 . 0 5}$.

\section{1) Compression test (Group 1) :}

A summary and descriptive analysis of these results and statistical analysis appeared in table (2). Analysis of the correlation between the loading values and corresponding displacment in Group 1 samples revealed highly significant storng positive correlation $(r=0.945)$ where $p$-value was $<0.001$

TABLE (2) Descriptive statistical analysis of Group 1 results

\begin{tabular}{|c|c|c|c|c|c|c|c|}
\hline Parameter & Mean & SD & SE & Maximum & Minimum & \multicolumn{2}{|c|}{$\begin{array}{c}\text { Correlation coefficient } \\
\text { between Yield load and yield } \\
\text { displacement values } \\
\text { (*Significant at P } \mathbf{0 . 0 5})\end{array}$} \\
\hline $\begin{array}{c}\text { Yield load } \\
\text { (Newtons) }\end{array}$ & $250.91 \mathrm{~N}$ & 55.98 & 17.70 & $355.53 \mathrm{~N}$ & $182.74 \mathrm{~N}$ & $\begin{array}{c}\mathbf{r} \\
\text { (Correlation } \\
\text { coefficient) }\end{array}$ & $\begin{array}{c}\text { P } \\
\text { (Propability ) }\end{array}$ \\
\hline $\begin{array}{c}\text { Yield displacement } \\
\text { (mm) }\end{array}$ & $11.40 \mathrm{~mm}$ & 6.02 & 1.90 & $19.60 \mathrm{~mm}$ & $3.80 \mathrm{~mm}$ & 0.945 & $<0.001^{*}$ \\
\hline $\begin{array}{c}\text { Compression } \\
\text { stiffness (N/mm) }\end{array}$ & $28.07 \mathrm{~N} / \mathrm{mm}$ & 14.30 & 4.44 & $48.30 \mathrm{~N} / \mathrm{mm}$ & $15.76 \mathrm{~N} / \mathrm{mm}$ & & \\
\hline
\end{tabular}




\section{2). Tension test (Group 2) :}

A summary and descriptive analysis of these results and statisticalanalysis appear in table (3). Analysis of the correlation between the loading values and corresponding displacment in group 2 samples revealed highly significant storng positive correlation $(r=0.984)$ where $p$-value was $<0.001$

\section{C) Correlation between both groups :}

In comparaison between two group according to yield load values as shown by the print out chart, both goups showed no stastically significant difference in mean yield load. Group 1 spécimens showed stastically signifiant higher mean yield displacment value than group 2 and group 2 samples presented stastically significant higher mean stiffness than in group 1 samples (Table 4) and (Fig.5),

TABLE (3) Descriptive statistical analysis of Group 1 results

\begin{tabular}{|c|c|c|c|c|c|c|c|}
\hline Parameter & Mean & SD & SE & Maximum & Minimum & \multicolumn{2}{|c|}{$\begin{array}{c}\text { Correlation coefficient } \\
\text { between Yield load and yield } \\
\text { displacement values } \\
\text { (*Significant at P } \leq \mathbf{0 5})\end{array}$} \\
\hline Yield load (Newtons) & $267.20 \mathrm{~N}$ & 49.42 & 15.63 & $322.23 \mathrm{~N}$ & $186.92 \mathrm{~N}$ & $\begin{array}{c}\mathbf{r} \\
\text { (Correlation } \\
\text { coefficient) }\end{array}$ & $\begin{array}{c}\text { P } \\
\text { (Propability) }\end{array}$ \\
\hline Yield displacement (mm) & $3.74 \mathrm{~mm}$ & 0.56 & 0.18 & $4.60 \mathrm{~mm}$ & $2.88 \mathrm{~mm}$ & 0.984 & $<0.001 *$ \\
\hline Tension stiffness $(\mathbf{N} / \mathbf{m m})$ & $72.03 \mathrm{~N} / \mathrm{mm}$ & 4.24 & 1.34 & $78.90 \mathrm{~N} / \mathrm{mm}$ & $64.90 \mathrm{~N} / \mathrm{mm}$ & & \\
\hline
\end{tabular}

TABLE (4) The means, standard deviation (SD) values and results of Student's t-test for the comparison between mean yield load, Yield displacement and Stiffness of the two groups.

\begin{tabular}{|c|c|c|c|c|c|}
\hline \multirow{2}{*}{ Parameter } & \multicolumn{2}{|c|}{ Group 1 } & \multicolumn{2}{c|}{ Group 2 } & \multirow{2}{*}{ P-value } \\
\cline { 2 - 5 } & Mean & SD & Mean & SD & 0.499 \\
\hline Yield load & $250.91 \mathrm{~N}$ & 55.98 & $267.20 \mathrm{~N}$ & 49.42 & $0.003 *$ \\
\hline Yield Displacment & $11.40 \mathrm{~mm}$ & 6.02 & 3.74 & 0.56 & $<0.001 *$ \\
\hline Stiffness & $28.07 \mathrm{~N} / \mathrm{mm}$ & 14.03 & $72.03 \mathrm{~N} / \mathrm{mm}$ & 4.24 & \multirow{2}{*}{} \\
\hline
\end{tabular}

*Significant at $P \leq 0.05$

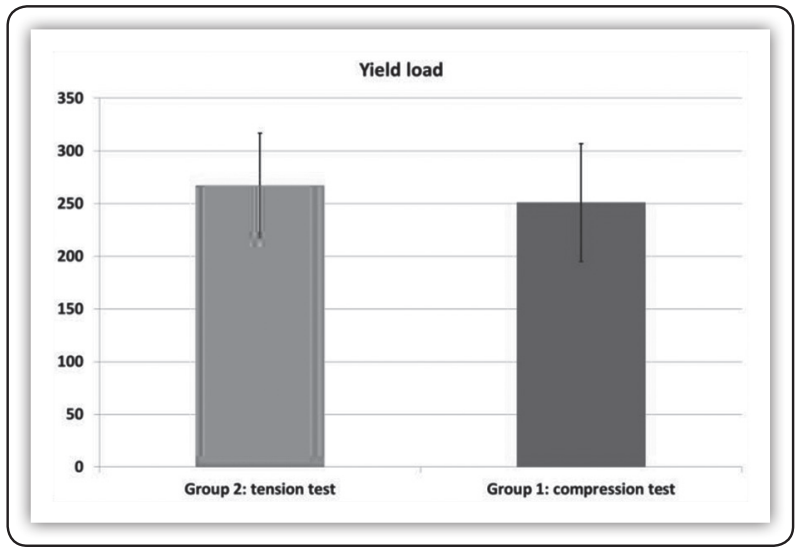

FIG (5) Comparison of mean yield load valuesfor both groups

\section{DISCUSSION}

Mandibular body fractures are considered common but there are discrepancies among the studies, such as epidemiological surveys, regarding their incidence ${ }^{(19)}$.

In the surgical treatment of mandibular fracturs, there are principles that should be followed for a successful outcome: fracture reduction (replacement of bone segments in their correct anatomical positions), fixation and containment of bone segments and immobilization at the fracture 
site $^{(20)}$. Champy et al (1978) $)^{(21)}$ have recommended functionally stable fixation using small miniplates through intraoral approaches, and the goal is to equalise tension and compression forces.

The use of miniplates is common nowadays but their behavior as tension bands is not completely understood. The anatomical and functional complexity of tension zones is a challenge, and lack of adequate fixation may lead to malunion, nonunion, less than ideal occlusion, and infection ${ }^{(22,23)}$. Miniplates have advantages in this area in that they require small intraoral incisions and minimise the risk of damage to the anatomical structures by using monocortical screws ${ }^{(21)}$. This study tested the mechanical properties of the three dimensional titanium miniplates in vitro in accordance with other in vitro tests that have been carried out to describe the biomechanical behaviour of supporting devices in a trial to validate the various modes of fixation for mandibular fractures ${ }^{(22-24)}$.

When evaluating the functional stability of the fixations by simulating the vectors and load intensity that they will be subjected to, there is a need for a model simulating the human mandible anatomy. In previous biomechanical studies for mandibular fractures variable sample sizes for testing samples were adopted. Some studies were carried out with a sample size of 5 hemi mandibles per group ${ }^{(25)}$.

Others used 10 hemi mandibles per group ${ }^{(14)}$. In the present study 10 adult sheep hemi mandibles were used for each group. Ten adult sheep mandibles with complete set of dentition were obtained, prepared and stored according to a previous study ${ }^{(14)}$. The coronoid process and condyle process of each sheep mandible were removed because difficulty of fixation on the test jigs ${ }^{(14,26)}$. Each mandible was divided into 2 hemi mandibles, thus 20hemimandibles were created. An oblique fracture line was created in each sample ${ }^{(14,32,27)}$. Wedge bone shape was made at inferior border of the mandible to prevent resistance of bone to the load during the testing process in to allow for only assessment of the mechanical properties of the fixation system. The fixation system was curved three dimensional titanium miniplates fixed in place by mono cortical titanium mini screws according to previous studies ${ }^{(28,33)}$. Reduction forceps were used to reduce the fractured sites, while all screw holes were drilled perpendicular to the mandible ${ }^{(29)}$ Drilling was 90 degree on bone surface, as in a previous studies it was reported that conventionally screws are inserted perpendicular to miniplates for better adaptation and maximum engagement of the threads of the screw into the bone to achieve more stability ${ }^{(30,31)}$. The application of the 3D titanium miniplates was carried out according to previously described methods ${ }^{(8-11)}$. Plates were applied in the mandibular body neutral zone. The fracture line and the fixation system positions were standardized for the experiment with the help of a prefabricated acrylic resin guide. This was to prevent errors due to variables in repetition of fracture line creation procedures and fixation system application thereby diminishing the possibility of alterations among them that might result from manual preparation of the samples. Also, at the time of miniplate screwing, the hemi-mandible was stabilized using drops of prefabricated self polymerizing resin and the miniplates positioned to make perforation possible. The same operator carried out all perforations ${ }^{(27,28)}$. The force mechanisms involved in chewing and the forces experienced by the bones involved are highly complex. Axial loads are those that produce compression forces or tensions in a structure. They act at points of contact that may serve as a screen or friction zone and consequently they may be influential in inducing rotation or displacement. In a clinical situation, it is important to be aware that effects of bending forces are far more important than those of axial forces. The third type of force involved is torque, which produces or tends to produce rotation or twisting ${ }^{(29)}$. 
It is known that in the fractures body and angle of the mandible, bone is normally subject to tension forces on its upper border and compression forces on its lower border ${ }^{(23,34)}$. In the present study, the results of the mean yield compression and tension stresses revealed that the used fixation system proofed to be highly efficient for supporting the fracture In during the period of osteosynthesis, as their point of deformation under load is far away from the reported maximum forces suitable for normal osteosynthesis processes. For body fractures, bite forces result in high bending moments, low torsion moments, and high shear forces .Displacement of the fracture fragments and effects of tension or compression at the site of fracture depend on the distance between loading point and fracture site ${ }^{(30,31)}$. The mandible is normally subjected to bending forces at its upper boundary part and to compression forces at its lower boundary part. Bite forces applied close to the fracture result in "negative" bending moments, which give a zone of compression in the alveolar region and a zone of tension at the lower border ${ }^{(31)}$. Bite forces applied at the other bite points result in "positive" bending moments, with a compression zone at the lower border and a tension zone in the alveolar region. A positive torsion moment resulted in lingual displacement of the border of the fragment posterior to the fracture in combination with buccal displacement of the border of the fragment anterior to the fracture. A negative torsion moment resulted in the opposite effect ${ }^{(32)}$.

In the present study, the greatest displacement registered in testing the groups is a response to the greater deformation they suffer, and this is especially demonstrated by the fact that in some of the tested samples the screws did not come out but remained in place until the limits of miniplate deformation had been attained. The explanation for this would be that the energy provoking deformation stemming from the force being applied and the way that the system uses that energy in deforming the plate, limits the forces that might eventually displace the screw so that it becomes an event that takes longer to occur. From the biomechanical point of view, such deformations in the plates are actually beneficial, but only up to the point where they reach the limits of their elasticity. Once that point has been passed, they no longer favor fixation stability because they are unable to go back to normal once the force has ceased and accordingly make the fracture reduction and fixation obtained by the treatment unfeasible ${ }^{(36)}$.

As reported by previous clinical studies, 3D systems demonstrated greater stability and resistance in comparison to one- or two-plate systems and provided a less invasive and more biocompatible alternative for one- or two-plate systems ${ }^{(35,32)}$. Within the limitation of this study and based upon the results, it is obviously evident that the proposed hypothesis considering that three dimensional miniplates would be an efficient alternative for other fixation techniques of mandibular body fractures was true. It is important to note that the laboratory techniques, such as the mechanical assays used in this study, are only auxiliary methods that determine potential differences among the different fixation systems. Therefore, the results of this study should be evaluated with further clinical trials,where the fracture characteristics, material availability, patient status, surgeon preferences, and other factors should be considered to determine the best treatment method.

\section{CONCLUSION}

- Three dimensional miniplates are easy to adjust, requires minimal tissue dissection thus least disturbance to the tissues.

- The results of this study show higher stability of the system against tension forces than compression forces.

- The three dimensional miniplates would be an efficient alternative for other fixation techniques of mandibular body fractures. 
- Further clinical studies are recommended to evaluate fracture characteristics, material availability, patient status, surgeon preferences, and other factors that could affect the treatment outcomes.

- Further biomechanical studies are recommended to evaluate the mechanical behavior of the used fixation system in other fractured regions of the mandible.

\section{REFERENCES}

1. Coletti D, Ord R. Treatment rationale for pathological fractures of the mandible: a series of 44 fractures. Int $\mathbf{J}$ Oral Maxillof Surg 2008; 37: 215-22.

2. Barron RP, Kainulainen VT, Gusenbauer AW, Hollenberg R, Sàndor GK. Fracture of glenoid fossa and traumatic dislocation of mandibular condyle into middle cranial fossa. Oral Surg, Oral Med, Oral Pathol, Oral Radiol, and Endod 2002; 93:640-42.

3. Meisami T, Sojat A, Sandor G, Lawrence H, Clokie C . Impacted third molars and risk of angle fracture. Int J Oral and Maxillofac Surg 2002; 31:140-44.

4. Lam DK, Sándor GK, Holmes HI, Evans AW Clokie CM. A review of bisphosphonate-associated osteonecrosis of the jaws and its management. J Canadian Dent Assoc 2007; 73: 417

5. Ellis E, Moos K, El-Attar A. Ten years of mandibular angle fractures: an analysis of 2137 cases. Oral Surg, Oral Med, Oral Pathol, Oral Radiol, and Endod.1985; 59: 120-29.

6. Fridrich K, Pena-Velasco G, Olson R. Changing trends with mandibular fractures: a review of 1067 cases. Oral Maxillofac Surg 1992; 50: 586-89.

7. Huelke D. Mechanics in the production of mandibular fractures: a study with the stress coat technique. I. Symphyseal impacts. J Dent Res 1964; 43: 437-46.

8. Huelke D, Harger J. Maxillofacial injuries: their nature and mechanisms of production. J Oral Surg. 1969; 27:451-60.

9. Evans F, Pedersen H, Lissner R. The role of tensile stress in the mechanism of femoral fractures. J Bone Joint Surg. $1951 ; 33: 485-8$

11. Jain MK, Manjunath KS, Bhagwan BK, Shah DK. Comparison of 3 dimensional and standard miniplate fixation in the management of mandibular fractures. J Oral Maxillofac Surg. 2010;68:1568-72.
12. Zix J, Lieger O, Iizuka T. Use of straight and curved 3-dimensional titanium miniplates for fracture fixation at the mandibular angle. J Oral Maxillofac Surg.2007;65:17581763.

13. Meyer C, Serhir L, Boutemi P. Experimental evaluation of three osteosynthesis devices used for stabilizing condylar fractures of the mandible. J Craniomaxillofac Surg. 2006;34:173-181. doi: 10.1016/j.jcms.2005.09.005.

14. Alkan A, et al. Biomechanical comparison of different plating techniques in repair of mandibular angle fractures. Oral Surg Oral Med Oral Pathol Oral Radiol Endod.2007;104:752-756.

15. Gerlach KL, Erle A, Eckelt U, Loukofta RA, Luhr HG Surgical management of mandibular, condylar neck and atrophic mandible fractures. In: Booth PW, Schendel SA, Hausamen J-E, editors. Textbook of Maxillofacial Surgery - Volume 1. 2nd Ed. London, UK: Churchill Livingstone; 2007. pp. 74-6.

16. Farmand $\mathrm{M}$,Dupoirieux L. The value of 3-dimensional plates in maxillofacial surgery.J Oral Maxillofac Surg.1992; 93:353 -7.

17. J. M. Wittenberg, D. P. Mukherjee, B. R. Smith, R. N. Kruse. Biomechanical evaluation of new fixation devices for mandibular angle fractures. Int. J. Oral Maxillofac. Surg. 1997; 26:68-73.

18. Ricalde P, Stephen L. Engroff, J. Anthony von Fraunhofer and Jeffrey C. Posnick,: Strength Analysis of Titanium and Resorbable Internal Fixation in a Mandibulotomy Model.J Oral Maxillofac Surg 2005; 63:1180-1183

19. Martini MZ, Takahashi A, Oliveira Neto HG, Carvalho Júnior JP, Curcio R, Shinohara EH. epidemiology of mandibular fractures treated in a Brazilian Level I Trauma Public Hospital in the City of São Paulo. Brazil.Braz Dent J. 2006; 17: 243-8.

20. Peterson JL, Ellis III E, Hupp JR, Tucker MR. Contemporary oral and maxillofacial surgery. 4th ed. Saint Louis: Mosby; 2002.

21. Champy M, Loddé P, Schmitt R. Mandibular osteosynthesis by miniature screwed plates via a buccal approach. J Maxillofac Surg. 1978; 6:14-9.

22. Moreno JC, Ferncindez A, Ortiz JA, Montalvo JJ. Complication rates associated with different treatments for mandibular fractures. J Oral Maxillofac Surg 2000; 58:273-280.

23. Al-Moraissi A, El-Sharkawy T, El-Ghareeb T: Three dimensional versus standard miniplate fixation in the 
management of mandibular angle fractures: a systematic review and meta-analysis. Int $\mathrm{J}$ Oral Maxillofac Surg.2014;43: 708-16.24

24. Madsen M, McdanielC,Haug R. A biomechanical evaluation of plating techniques used for reconstructing mandibular symphysis/parasymphysis fractures.J Oral Maxillofac Surg. 2008; 66: 2012-9.

25. Haug R, Peterson G,Goltz M: A biomechanical evaluation of mandibular condyle fracture plating techniques. J Oral Maxillofac Surg 2002; 60:73-80.

26. Rudderman R, Mullen R, Phillips J. The biophysics of mandibular fractures: an evolution toward understanding. Plast Reconstr Surg 2008; 121:596-607.

27. Marcela R, Lauria A, Sato F, Moriera R: Biomechanical analysis of different fixation techniques for treatment of mandibular body fractures. Braz. J Oral Sci 2013; 12:80-83.

28. Leandro B, Santana E, Antonio J, William A : Biomechanical in vitro evaluation of three stable internal fixation techniques used in sagittal osteotomy of the mandibular ramus: a study in sheep mandibles. J Appl Oral Sci 2012; 50:17-34

29. 29. De Oliveira K, De Moraes P, Da Silva J, De Queiroz system three-dimensional miniplates in anterior mandibular fractures. Int J Oral Maxillofac Surg 2013; 10:1-8.
30. Muñante L, Passeri L : Biomechanical Comparison of Four Mandibular Angle Fracture Fixation Techniques. Craniomaxillofac Trauma Reconst. 2015; 8:123.

31. Kalfarentzos EF, Deligianni D, Mitros G, Tyllianakis M: Biomechanical evaluation of plating techniques for fixing mandibular angle fractures: the introduction of a new 3D plate approach. Oral Maxillofac Surg 2009; 13:139-44

32. Ellis III E. Treatment methods for fractures of the mandibular angle. Int J Oral Maxillofac Surg.1999; 28: 243-52.

33. Schatzker J, Brudnicki J. The evolution of AO/ASIF views on fracture treatment (in Polish). Chir Narzadow Ruchu Ortop Pol 2006; 71:275-9.

34. Tams J, van Loon JP, Rozema FR, Otten E, Bos RR. A three-dimensional study of loads across the fracture for different fracture sites of the mandible. Br J Oral Maxillofac Surg 1996; 34:400-5.

35. Tams J, van Loon J-P, Otten E, et al. A Three-dimensional study of bending and torsion moments for different fracture sites of the mandible: An in vitro study. Int J Oral Maxillofac Surg 1997; 26:383.

36. Guimond C, Johnson JV, Marchena JM. Fixation of mandibular angle fractures with $2.0 \mathrm{~mm} 3$ dimensional curved angle strut plate. J Oral Maxillofac Surg 2005; 63:209. 
